\title{
Proof Of Fermat's Last Theorem By Choosing Two Unknowns in the Integer Solution Are Prime Exponents
}

\author{
Dr.k sreedevi, Dr.braou, Mr. Thiruchinarpalli Srinivas, Dr.Braou \\ Dept. of Mathematics, Hyderabad, Telangana, India \\ *Correspondence:sri.du.1980@gmail.com
}

In this paper we are revisits well known problem in number theory ' proof of Fermat's last theorem ' with different perspective .Also we are presented for $\mathrm{n}>2$, Diophantine equations $\mathrm{K}\left(x^{n}+y^{n}\right)=z^{n}$ and $x^{n}+y^{n}=L z^{n}$ are satisfied by some positive prime exponents of $\mathrm{x}, \mathrm{y}, \mathrm{z}$ with some sufficient values of $\mathrm{K}$ and $\mathrm{L}$. But it is not possible to find positive integers $\mathrm{x}$, $\mathrm{y}$ and $\mathrm{z}$, which are satisfies above equations with exactly $\mathrm{K}=1$ and $\mathrm{L}=1$. Clearly it proves the Fermat's last theorem, which states that No positive integers of $\mathrm{x}, \mathrm{y}, \mathrm{z}$ are satisfies the equation $x^{n}+y^{n}=z^{n}$ for $\mathrm{n}>2$.

Keywords: Fermat's Last theorem, Diophantine equation, Prime Exponents.

\section{Introduction}

We know that every integer is either prime or product of primes. Also we can verify easily above equations $\mathrm{K}\left(x^{n}+\right.$ $\left.y^{n}\right)=z^{n}$ and $x^{n}+y^{n}=L z^{n}$ are satisfied by some positive integers $\mathrm{x}, \mathrm{y}, \mathrm{z}$

(which are primes or product of primes with exponent power is 1) with some sufficient values of $K$ and $L$ are not equal to 1 for $n>2$. i.e we can verify Fermat's last theorem by choosing of $\mathrm{x}, \mathrm{y}, \mathrm{z}$ (exponent power is 1) to solve for $\mathrm{K}$ and L. Some examples are represented in below table.

TABLE 1:

\begin{tabular}{llllll}
\hline Choose & Choose & Choose & Choose & $\mathrm{K}$ & $\mathrm{L}=$ \\
n value & x value & $\mathrm{y}$ value & $\mathrm{z}$ value & $=\frac{z^{n}}{x^{n}+y^{n}}$ & $\frac{x^{n}+y^{n}}{z^{n}}$ \\
3 & 2 & 3 & 5 & 3.57 & 0.28 \\
3 & 3 & 4 & 5 & 1.37 & 0.728 \\
3 & 2 & 5 & 7 & 2.57 & 0.3877 \\
3 & 3 & 5 & 7 & 2.2565 & 0.4431 \\
4 & 3 & 5 & 11 & 8.7565 & 0.1141 \\
4 & 3 & 6 & 7 & 1.41152 & 0.7084 \\
4 & 5 & 4 & 6 & 1.1428 & 0.875 \\
\hline
\end{tabular}

Now we can solve for the values of $\mathrm{K}$ and $\mathrm{L}$ by choosing $\mathrm{x}$ and $\mathrm{y}$ are prime exponents whose power is more than one for proving Fermat's Last theorem.

Working rule:
Consider the Diophantine equations $\mathrm{K}\left(x^{n}+y^{n}\right)=z^{n}$ and $x^{n}+y^{n}=L z^{n}$. we are worked for finding ' $z$ ', ' $K$ ', ' $L$ ' values by choosing of $\mathrm{x}$ and $\mathrm{y}$ are prime exponents of 2,3 and 5 .

Case 1: $\mathrm{x}, \mathrm{y}$ is represented by Exponent of 2

Theorem 1: Let $\mathrm{x}=2^{p}, y=2^{q}, z=2^{p}\left(1+2^{n(q-p)}\right), K=$ $\left(1+2^{n(q-p)}\right)^{n-1}$ are satisfies the equation $\mathrm{K}\left(x^{n}+y^{n}\right)=z^{n}$ for all integer values of $\mathrm{p} \geq 1, \mathrm{q} \geq 1, p<q, \mathrm{n} \geq 1$.

Proof: Let $\mathrm{x}=2^{p}, y=2^{q}$

Consider $x^{n}+y^{n}=\left(2^{\mathrm{p}}\right)^{\mathrm{n}}+\left(2^{\mathrm{q}}\right)^{\mathrm{n}}$

$$
\begin{aligned}
& x^{n}+y^{n}=2^{n p}+2^{n q} \\
& x^{n}+y^{n}=2^{n p}\left(1+2^{n(q-p)}\right)
\end{aligned}
$$

Now we can multiply both side with $\left(1+2^{n(q-p)}\right)^{n-1}$, we obtain that

$$
\begin{aligned}
& \left(1+2^{n(q-p)}\right)^{n-1}\left(x^{n}+y^{n}\right)=2^{n p}\left(1+2^{n(q-p)}\right)^{n} \\
& \left(1+2^{n(q-p)}\right)^{n-1}\left(x^{n}+y^{n}\right)=\left(2^{p}\left(1+2^{n(q-p)}\right)\right)^{n}
\end{aligned}
$$

Without loss generality, we can assume that $\mathrm{K}=$ $\left(1+2^{n(q-p)}\right)^{n-1}$ and $\mathrm{z}=2^{p}\left(1+2^{n(q-p}\right)$

Then above equation is reduced as $\mathrm{K}\left(x^{n}+y^{n}\right)=z^{n}$. we can easily verify the Proof of Fermat's Last theorem by substitute the values of $p, q$ and $n$ to solve for $K$ value (It must be not equal to one, for all values of $\mathrm{p}, \mathrm{q}$ and $\mathrm{n}$.)

Lemma 1: Without loss of generality, from above theorem replace $\mathrm{q}=\mathrm{p}+1$,

Let $\quad x=2^{p}, y=2^{p+1}, z=2^{p}\left(1+2^{n}\right), K=\left(1+2^{n}\right)^{n-1}$ are satisfies the equation

$\mathrm{K}\left(x^{n}+y^{n}\right)=z^{n}$ for all integar values of $\mathrm{p} \geq 1, \mathrm{n} \geq 1$.

Proof: Let $\mathrm{x}=2^{p}, y=2^{p+1}$

Consider $x^{n}+y^{n}=\left(2^{\mathrm{p}}\right)^{\mathrm{n}}+\left(2^{\mathrm{p}+1}\right)^{\mathrm{n}}$

$$
x^{n}+y^{n}=2^{n p}+2^{n p+n}
$$

[Received 01 June 2020; Accepted 28 Oct 2020; Published (online) 31 Dec 2020] Publisher's Note: RCLSS stays neutral regard to jurisdictional claims published maps (c) (1) 


$$
x^{n}+y^{n}=2^{n p}\left(1+2^{n}\right)
$$

Now we can multiply both side with $\left(1+2^{n}\right)^{n-1}$,we obtain that

$$
\begin{aligned}
& \left(1+2^{n}\right)^{n-1}\left(x^{n}+y^{n}\right)=2^{n p}\left(1+2^{n}\right)^{n} \\
& \left(1+2^{n}\right)^{n-1}\left(x^{n}+y^{n}\right)=\left(2^{p}\left(1+2^{n}\right)\right)^{n}
\end{aligned}
$$

Without loss generality, we can assume that $\mathrm{K}=\left(1+2^{n}\right)^{n-1}$ and $\mathrm{z}=2^{p}\left(1+2^{n}\right)$

Then above equation is reduced as $\mathrm{K}\left(x^{n}+y^{n}\right)=z^{n}$.

TABLE 2: We can verify the triplets $(\mathrm{x}, \mathrm{y}, \mathrm{z})$ are satisfies above equation by taking some values of $\mathrm{p} \& \mathrm{n}$

\begin{tabular}{llllllll}
\hline $\mathrm{n}$ & $\mathrm{p}$ & $\mathrm{X}$ & $\mathrm{Y}=$ & $\mathrm{Z}=$ & $\mathrm{K}=$ & $\mathrm{K}\left(x^{n}+\right.$ & $z^{n}$ \\
& & $2^{p+1}$ & $2^{p}(1+(1+$ & $\left.y^{n}\right)$ & & \\
& & $2^{p}$ & & $\left.2^{n}\right)$ & $\left.2^{n}\right)^{n-1}$ & & \\
1 & 1 & 2 & 4 & 6 & 1 & 6 & 6
\end{tabular}

$\begin{array}{llllllll}2 & 1 & 2 & 4 & 10 & 5 & 100 & 100 \\ 2 & 2 & 4 & 8 & 20 & 5 & 400 & 400 \\ 3 & 1 & 2 & 4 & 18 & 81 & 5832 & 5832 \\ 3 & 2 & 4 & 8 & 36 & 81 & 46656 & 46656 \\ 4 & 1 & 2 & 4 & 34 & 4913 & 1336336 & 1336336 \\ 5 & 2 & 4 & 8 & 132 & 11859 & 4007464 & 4007464 \\ & & & & & 21 & 2432 & 2432 \\ 6 & 2 & 4 & 8 & 260 & 10737 & 3089157 & 3089157 \\ & & & & & 41825 & 7600000 & 7600000 \\ & & & & & & 0 & 0\end{array}$

Clearly $\mathrm{K}=1$, only for $\mathrm{n}=1$. And all other cases $\mathrm{K}$ is more than 1. It follows that Fermat's last theorem is verified for " No positive integers $\mathrm{x}, \mathrm{y}, \mathrm{z}$ are satisfies the equation $x^{n}+y^{n}=$ $z^{n}$ for any integer $n>2$.

THEOREM 2: Let $\mathrm{x}=2^{p}, y=2^{q}, z=2^{p}, L=1+2^{n(q-p)}$ are satisfies the equation

$x^{n}+y^{n}=L z^{n}$ for all integer values of $\mathrm{p} \geq 1, \mathrm{q} \geq 1, \mathrm{n} \geq 1$.

Proof: Let $\mathrm{x}=2^{p}, y=2^{q}$

Consider $x^{n}+y^{n}=\left(2^{\mathrm{p}}\right)^{\mathrm{n}}+\left(2^{\mathrm{q}}\right)^{\mathrm{n}}$

$$
\begin{aligned}
& x^{n}+y^{n}=2^{n p}+2^{n q} \\
& x^{n}+y^{n}=2^{n p}\left(1+2^{n(q-p)}\right)
\end{aligned}
$$

Without loss generality, we can assume that $\mathrm{L}=1+2^{n(q-p)}$ and $\mathrm{z}=2^{p}$

Then above equation is reduced as $x^{n}+y^{n}=L z^{n}$. we can easily verify the Proof of Fermat's Last theorem by substitute the values of $p, q$ and $n$ to solve for $L$ value (It must be not equal to one, for all values of $\mathrm{p}, \mathrm{q}$ and $\mathrm{n}$.)

Lemma 2: From above theorem, without loss of generality replace $\mathrm{q}=\mathrm{p}+1$

Let $\mathrm{x}=2^{p}, y=2^{p+1}, z=2^{p}, L=1+2^{n}$ are satisfies the equation

$x^{n}+y^{n}=L z^{n}$ for all integar values of $\mathrm{p} \geq 1, \mathrm{n} \geq 1$.

Proof: Let $\mathrm{x}=2^{p}, y=2^{p+1}$

Consider $x^{n}+y^{n}=\left(2^{\mathrm{p}}\right)^{\mathrm{n}}+\left(2^{\mathrm{p}+1}\right)^{\mathrm{n}}$

$$
\begin{aligned}
& x^{n}+y^{n}=2^{n p}+2^{n p+n} \\
& x^{n}+y^{n}=2^{n p}\left(1+2^{n}\right)
\end{aligned}
$$

Without loss generality, we can assume that $\mathrm{L}=1+2^{n}$ and $\mathrm{z}=2^{p}$

Then above equation is reduced as $x^{n}+y^{n}=L z^{n}$

TABLE 3: We can verify the triplets $(\mathrm{x}, \mathrm{y}, \mathrm{z})$ are satisfies above equation by taking some values of $p \& n$

\begin{tabular}{llllllll}
\hline $\mathrm{n}$ & $\mathrm{p}$ & $\mathrm{X}=$ & $\mathrm{Y}=$ & $\mathrm{Z}=$ & $L$ & $x^{n}+y^{n}$ & $\mathrm{Lz}{ }^{n}$ \\
& & $2^{p}$ & $2^{p+1}$ & $2^{p}$ & $\begin{array}{l}\text { } \\
+2^{n} \\
\end{array}$ \\
1 & 1 & 2 & 4 & 2 & 3 & 6 & 6 \\
2 & 1 & 2 & 4 & 2 & 5 & 20 & 20 \\
2 & 2 & 4 & 8 & 4 & 5 & 80 & 80 \\
3 & 1 & 2 & 4 & 2 & 9 & 72 & 72 \\
3 & 2 & 4 & 8 & 4 & 9 & 576 & 576 \\
4 & 2 & 4 & 8 & 4 & 17 & 4352 & 4352 \\
5 & 2 & 4 & 8 & 4 & 33 & 33792 & 33792 \\
6 & 2 & 4 & 8 & 4 & 65 & 266240 & 266240 \\
7 & 2 & 4 & 8 & 4 & 129 & 2113536 & 2113536 \\
8 & 2 & 4 & 8 & 4 & 257 & 1684275 & 1684275 \\
& & & & & & 2 & 2 \\
9 & 2 & 4 & 8 & 4 & 513 & 1344798 & 1344798 \\
& & & & & & 72 & 72
\end{tabular}

Clearly $\mathrm{L}$ is greater than 1 . It follows that Fermat's last theorem is verified for " No positive integers $x, y, z$ are satisfies the equation $x^{n}+y^{n}=z^{n}$ for any integar $\mathrm{n}>2$.

Case 2: $x, y$ are represented by Exponent of 3

Theorem 3: Let $\mathrm{x}=3^{p}, y=3^{q}, z=3^{p}\left(1+3^{n(q-p)}\right), K=$ $\left(1+3^{n(q-p)}\right)^{n-1}$ are satisfies the equation $\mathrm{K}\left(x^{n}+y^{n}\right)=z^{n}$ for all integer values of $\mathrm{p} \geq 1, \mathrm{q}>p, \mathrm{n} \geq 1$.

Proof: Let $\mathrm{x}=3^{p}, y=3^{q}$

Consider $x^{n}+y^{n}=\left(3^{\mathrm{p}}\right)^{\mathrm{n}}+\left(3^{\mathrm{q}}\right)^{\mathrm{n}}$

$$
\begin{aligned}
& x^{n}+y^{n}=3^{n p}+3^{n q} \\
& x^{n}+y^{n}=3^{n p}\left(1+3^{n(q-p)}\right)
\end{aligned}
$$


Now we can multiply both side with $\left(1+3^{n(q-p)}\right)^{n-1}$, we obtain that

$$
\begin{aligned}
& \left(1+3^{n(q-p)}\right)^{n-1}\left(x^{n}+y^{n}\right)=3^{n p}\left(1+3^{n(q-p)}\right)^{n} \\
& \left(1+3^{n(q-p)}\right)^{n-1}\left(x^{n}+y^{n}\right)=\left(3^{p}\left(1+3^{n(q-p)}\right)\right)^{n}
\end{aligned}
$$

Without loss generality, we can assume that $\mathrm{K}=(1+$ $\left.3^{n(q-p)}\right)^{n-1}$ and $\mathrm{z}=3^{p}\left(1+3^{n(q-p)}\right)$

Then above equation is reduced as $\mathrm{K}\left(x^{n}+y^{n}\right)=z^{n}$. we can easily verify the Proof of Fermat's Last theorem by substitute the values of $\mathrm{p}, \mathrm{q}$ and $\mathrm{n}$ to solve for $\mathrm{K}$ value (It must be not equal to one, for all values of $\mathrm{p}, \mathrm{q}$ and $\mathrm{n}$.)

Lemma 3: Without Loss of generality, from above theorem replace $\mathrm{q}=\mathrm{p}+1$,

Let $\quad \mathrm{x}=3^{p}, y=3^{p+1}, z=3^{p}\left(1+3^{n}\right), K=\left(1+3^{n}\right)^{n-1}$ are satisfies the equation

$\mathrm{K}\left(x^{n}+y^{n}\right)=z^{n}$ for all integar values of $\mathrm{p} \geq 1, \mathrm{n} \geq 1$.

Proof: Let $\mathrm{x}=3^{p}, y=3^{p+1}$

Consider $x^{n}+y^{n}=\left(3^{\mathrm{p}}\right)^{\mathrm{n}}+\left(3^{\mathrm{p}+1}\right)^{\mathrm{n}}$

$$
\begin{aligned}
& x^{n}+y^{n}=3^{n p}+3^{n p+n} \\
& x^{n}+y^{n}=3^{n p}\left(1+3^{n}\right)
\end{aligned}
$$

Now we can multiply both side with $\left(1+3^{n}\right)^{n-1}$, we obtain that

$$
\begin{aligned}
& \left(1+3^{n}\right)^{n-1}\left(x^{n}+y^{n}\right)=3^{n p}\left(1+3^{n}\right)^{n} \\
& \left(1+3^{n}\right)^{n-1}\left(x^{n}+y^{n}\right)=\left(3^{p}\left(1+3^{n}\right)\right)^{n}
\end{aligned}
$$

Without loss generality, we can assume that $\mathrm{K}=\left(1+3^{n}\right)^{n-1}$ and $\mathrm{z}=3^{p}\left(1+3^{n}\right)$

Then above equation is reduced as $\mathrm{K}\left(x^{n}+y^{n}\right)=z^{n}$

TABLE 4: We can verify the triplets $(x, y, z)$ are satisfies above equation by taking some values of $\mathrm{p} \& \mathrm{n}$

\begin{tabular}{llllllll}
\hline $\mathrm{n}$ & $\mathrm{p}$ & $\mathrm{X}=$ & $\mathrm{Y}=$ & $\mathrm{Z}=$ & $\mathrm{K}=$ & $\mathrm{K}\left(x^{n}+\right.$ & \multicolumn{1}{c}{$Z^{n}$} \\
& & $3^{p}$ & $3^{p+1}$ & \multicolumn{3}{l}{$3^{p}\left(1+\left(1+y^{n}\right)\right.$} \\
& & \multicolumn{5}{c}{$\left.3^{n}\right)$} & $\left.3^{n}\right)^{n-}$ \\
1 & 1 & 3 & 9 & 12 & 1 & 12 & 12 \\
2 & 1 & 3 & 9 & 30 & 10 & 900 & 900 \\
2 & 2 & 9 & 27 & 90 & 10 & 8100 & 8100 \\
3 & 1 & 3 & 9 & 84 & 784 & 592704 & 592704 \\
3 & 2 & 9 & 27 & 252 & 784 & 1600300 & 1600300 \\
& & & & & & 8 & 8 \\
4 & 1 & 3 & 9 & 246 & 551 & 3662186 & 3662186 \\
& & & & & 368 & 256 & 256 \\
4 & 2 & 9 & 27 & 738 & 551 & 2966370 & 2966370 \\
& & & & & 368 & 86736 & 86736 \\
\hline
\end{tabular}

\begin{tabular}{llllllll}
\hline 4 & 3 & 27 & 81 & 2214 & 551 & 2402760 & 2402760 \\
& & & & 368 & 4025616 & 4025616 \\
\hline
\end{tabular}

Clearly $\mathrm{K}=1$, only for $\mathrm{n}=1$. And all other cases $\mathrm{K}$ is more than 1. It follows that Fermat's last theorem is verified for "No positive integers $\mathrm{x}, \mathrm{y}, \mathrm{z}$ are satisfies the equation $x^{n}+y^{n}=$ $z^{n}$ for any integar $\mathrm{n}>2$.

Theorem 4: Let $\mathrm{x}=3^{p}, y=3^{q}, z=3^{p}, L=1+3^{n(q-p)}$ are satisfies the equation

$x^{n}+y^{n}=L z^{n}$ for all integer values of $\mathrm{p} \geq 1, \mathrm{q}>p, \mathrm{n} \geq 1$.

Proof: Let $\mathrm{x}=3^{p}, y=3^{q}$

Consider $x^{n}+y^{n}=\left(3^{\mathrm{p}}\right)^{\mathrm{n}}+\left(3^{\mathrm{q}}\right)^{\mathrm{n}}$

$$
\begin{aligned}
& x^{n}+y^{n}=3^{n p}+3^{n q} \\
& x^{n}+y^{n}=3^{n p}\left(1+3^{n(q-p)}\right)
\end{aligned}
$$

Without loss generality, we can assume that $\mathrm{L}=1+3^{n(q-p)}$ and $\mathrm{z}=3^{p}$

Then above equation is reduced as $x^{n}+y^{n}=L z^{n}$. we can easily verify the Proof of Fermat's Last theorem by substitute the values of $p, q$ and $n$ to solve for $L$ value (It must be not equal to one, for all values of $\mathrm{p}, \mathrm{q}$ and $\mathrm{n}$.)

Lemma 4: Without loss of generality replace $\mathrm{q}=\mathrm{p}+1$,

Let $\mathrm{x}=3^{p}, y=3^{p+1}, z=3^{p}, L=1+3^{n}$ are satisfies the equation

$x^{n}+y^{n}=L z^{n}$ for all integer values of $\mathrm{p} \geq 1, \mathrm{n} \geq 1$.

Now we can go to prove that $x^{n}+y^{n}=L z^{n}$ for all integer values of $\mathrm{p} \geq 1, \mathrm{n} \geq 1$.

Proof: Let $\mathrm{x}=3^{p}, y=3^{p+1}$

\begin{tabular}{|c|c|c|c|c|c|c|c|}
\hline $\bar{n}$ & $\bar{p}$ & $\begin{array}{l}\mathrm{X}= \\
3^{p}\end{array}$ & $\begin{array}{l}\mathrm{Y}= \\
3^{p+1}\end{array}$ & $\begin{array}{l}\mathrm{Z}= \\
3^{p}\end{array}$ & $\begin{array}{l}L \\
=1 \\
+3^{n}\end{array}$ & $x^{n}+y^{n}$ & $\mathrm{~L} z^{n}$ \\
\hline 1 & 1 & 3 & 9 & 3 & 4 & 12 & 12 \\
\hline 2 & 1 & 3 & 9 & 3 & 10 & 90 & 90 \\
\hline 2 & 2 & 9 & 27 & 9 & 10 & 810 & 810 \\
\hline 3 & 1 & 3 & 9 & 3 & 28 & 756 & 756 \\
\hline 3 & 2 & 9 & 27 & 9 & 28 & 20412 & 20412 \\
\hline 4 & 2 & 9 & 27 & 9 & 82 & 538002 & 538002 \\
\hline 4 & 3 & 27 & 81 & 27 & 82 & 4357816 & 4357816 \\
\hline & & & & & & 2 & 2 \\
\hline
\end{tabular}

Consider $x^{n}+y^{n}=\left(3^{\mathrm{p}}\right)^{\mathrm{n}}+\left(3^{\mathrm{p}+1}\right)^{\mathrm{n}}$

$$
\begin{aligned}
& x^{n}+y^{n}=3^{n p}+3^{n p+n} \\
& x^{n}+y^{n}=3^{n p}\left(1+3^{n}\right)
\end{aligned}
$$

Without loss generality, we can assume that $\mathrm{L}=1+3^{n}$ and $\mathrm{z}=3^{p}$

Then above equation is reduced as $x^{n}+y^{n}=L z^{n}$

TABLE 5: We can verify the triplets $(\mathrm{x}, \mathrm{y}, \mathrm{z})$ are satisfies above equation by taking some values of $\mathrm{p} \& \mathrm{n}$ 


\begin{tabular}{llllllll}
\hline 4 & 4 & 81 & 243 & 81 & 82 & 3529831 & 3529831 \\
& & & & & & 122 & 122 \\
5 & 1 & 3 & 9 & 3 & 244 & 59292 & 59292 \\
5 & 2 & 9 & 27 & 9 & 244 & 1440795 & 1440795 \\
& & & & & & 6 & 6 \\
5 & 3 & 27 & 81 & 27 & 244 & 3501133 & 3501133 \\
& & & & & & 308 & 308 \\
6 & 1 & 3 & 9 & 3 & 730 & 532170 & 532170 \\
\hline
\end{tabular}

Clearly $\mathrm{L}$ is greater than 1 . It follows that Fermat's last theorem is verified for " No positive integers $\mathrm{x}, \mathrm{y}, \mathrm{z}$ are satisfies the equation $x^{n}+y^{n}=z^{n}$ for any integar $\mathrm{n}>2$.

Case 3: $\mathrm{x}, \mathrm{y}$ is represented by Exponent of 5

Theorem 5: Let $\mathrm{x}=5^{p}, y=5^{q}, z=5^{p}\left(1+5^{n(q-p)}\right)$, $K=\left(1+5^{n(q-p)}\right)^{n-1}$ are satisfies the equation $\mathrm{K}\left(x^{n}+\right.$ $\left.y^{n}\right)=z^{n}$ for all integer values of $\mathrm{p} \geq 1, \mathrm{q}>\mathrm{p}, \mathrm{n} \geq 1$.

Proof: Let $\mathrm{x}=5^{p}, y=5^{q}$

Consider $x^{n}+y^{n}=\left(5^{\mathrm{p}}\right)^{\mathrm{n}}+\left(5^{\mathrm{q}}\right)^{\mathrm{n}}$

$$
\begin{aligned}
& x^{n}+y^{n}=5^{n p}+5^{n q} \\
& x^{n}+y^{n}=5^{n p}\left(1+5^{n(q-p)}\right)
\end{aligned}
$$

Now we can multiply both side with $\left(1+5^{n(q-p)}\right)^{n-1}$, we obtain that

$$
\begin{gathered}
\left(1+5^{n(q-p)}\right)^{n-1}\left(x^{n}+y^{n}\right)=5^{n p}\left(1+5^{n(q-p)}\right)^{n} \\
\left(1+5^{n(q-p)}\right)^{n-1}\left(x^{n}+y^{n}\right)=\left(5^{p}\left(1+5^{n(q-p)}\right)\right)^{n}
\end{gathered}
$$

Without loss generality, we can assume that $\mathrm{K}=(1+$ $\left.5^{n(q-p)}\right)^{n-1}$ and $\mathrm{z}=5^{p}\left(1+5^{n(q-p)}\right)$

Then above equation is reduced as $\mathrm{K}\left(x^{n}+y^{n}\right)=z^{n}$. we can easily verify the Proof of Fermat's Last theorem by substitute the values of $p, q$ and $n$ to solve for $\mathrm{K}$ value (It must be not equal to one, for all values of $\mathrm{p}, \mathrm{q}$ and $\mathrm{n}$.)

Lemma 5: Without loss of generality replace $q=p+1$,

Let $\quad \mathrm{x}=5^{p}, y=5^{p+1}, z=5^{p}\left(1+5^{n}\right), K=(1+$ $\left.5^{n}\right)^{n-1}$ are satisfies the equation $\mathrm{K}\left(x^{n}+y^{n}\right)=z^{n}$ for all integer values of $\mathrm{p} \geq 1, \mathrm{n} \geq 1$.

Proof: Let $\mathrm{x}=5^{p}, y=5^{p+1}$

Consider $x^{n}+y^{n}=\left(5^{\mathrm{p}}\right)^{\mathrm{n}}+\left(5^{\mathrm{p}+1}\right)^{\mathrm{n}}$

$$
\begin{aligned}
& x^{n}+y^{n}=5^{n p}+5^{n p+n} \\
& x^{n}+y^{n}=5^{n p}\left(1+5^{n}\right)
\end{aligned}
$$

Now we can multiply both side with $\left(1+5^{n}\right)^{n-1}$, we obtain that

$$
\begin{aligned}
& \left(1+5^{n}\right)^{n-1}\left(x^{n}+y^{n}\right)=5^{n p}\left(1+5^{n}\right)^{n} \\
& \left(1+5^{n}\right)^{n-1}\left(x^{n}+y^{n}\right)=\left(5^{p}\left(1+5^{n}\right)\right)^{n}
\end{aligned}
$$

Without loss generality, we can assume that $\mathrm{K}=\left(1+5^{n}\right)^{n-1}$ and $\mathrm{z}=5^{p}\left(1+5^{n}\right)$

Then above equation is reduced as $\mathrm{K}\left(x^{n}+y^{n}\right)=z^{n}$

TABLE 6: We can verify the triplets $(x, y, z)$ are satisfies above equation by taking some values of $\mathrm{p} \& \mathrm{n}$

\begin{tabular}{llllllll}
\hline $\mathrm{n}$ & $\mathrm{p}$ & $\mathrm{X}=$ & $\mathrm{Y}=$ & $\mathrm{Z}=$ & $\mathrm{K}=$ & $\mathrm{K}\left(x^{n}+\right.$ & \multicolumn{1}{c}{$z^{n}$} \\
& & $5^{p}$ & $5^{p+1}$ & $5^{p}\left(1+\begin{array}{ll}(1+ \\
\left.y^{n}\right)\end{array}\right.$ & \\
& & & & $\left.5^{n}\right)$ & $\left.5^{n}\right)^{n-1}$ & & \\
1 & 1 & 5 & 25 & 30 & 1 & 30 & 30 \\
2 & 1 & 5 & 25 & 130 & 26 & 16900 & 16900 \\
2 & 2 & 25 & 125 & 650 & 26 & 422500 & 422500 \\
3 & 1 & 5 & 25 & 630 & 1587 & 25004700 & 25004700 \\
& & & & & & 0 & 0 \\
3 & 2 & 25 & 125 & 3150 & 1587 & 31255875 & 31255875 \\
& & & & & 000 & 000 \\
4 & 1 & 5 & 25 & 3130 & 24531 & 95979249 & 95979249 \\
& & & & & 437 & 610000 & 610000 \\
\hline
\end{tabular}

Clearly $\mathrm{K}=1$, only for $\mathrm{n}=1$. And all other cases $\mathrm{K}$ is more than 1. It follows that Fermat's last theorem is verified for "No positive integers $\mathrm{x}, \mathrm{y}, \mathrm{z}$ are satisfies the equation $x^{n}+y^{n}=$ $z^{n}$ for any integar $\mathrm{n}>2$.

Theorem 6: Let $x=5^{p}, y=5^{q}, z=5^{p}, L=1+5^{n(q-p)}$ are satisfies the equation

$x^{n}+y^{n}=L z^{n}$ for all integer values of $\mathrm{p} \geq 1, \mathrm{q}>\mathrm{p}, \mathrm{n} \geq 1$.

Proof: Let $\mathrm{x}=5^{p}, y=5^{q}$

Consider $x^{n}+y^{n}=\left(5^{\mathrm{p}}\right)^{\mathrm{n}}+\left(5^{\mathrm{q}}\right)^{\mathrm{n}}$

$$
\begin{aligned}
& x^{n}+y^{n}=5^{n p}+5^{n q} \\
& x^{n}+y^{n}=5^{n p}\left(1+5^{n(q-p)}\right)
\end{aligned}
$$

Without loss generality, we can assume that $\mathrm{L}=1+5^{n(q-p)}$ and $\mathrm{z}=5^{p}$

Then above equation is reduced as $x^{n}+y^{n}=L z^{n}$. we can easily verify the Proof of Fermat's Last theorem by substitute the values of $p, q$ and $n$ to solve for $L$ value (It must be not equal to one, for all values of $\mathrm{p}, \mathrm{q}$ and $\mathrm{n}$.)

Lemma 6: Without loss of generality from above theorem replace $\mathrm{q}=\mathrm{p}+1$

Let $x=5^{p}, y=5^{p+1}, z=5^{p}, L=1+5^{n}$ are satisfies the equation

$x^{n}+y^{n}=L z^{n}$ for all integar values of $\mathrm{p} \geq 1, \mathrm{n} \geq 1$.

Proof: Let $\mathrm{x}=5^{p}, y=5^{p+1}$

Consider $x^{n}+y^{n}=\left(5^{\mathrm{p}}\right)^{\mathrm{n}}+\left(5^{\mathrm{p}+1}\right)^{\mathrm{n}}$

$$
\begin{aligned}
& x^{n}+y^{n}=5^{n p}+5^{n p+n} \\
& x^{n}+y^{n}=5^{n p}\left(1+5^{n}\right)
\end{aligned}
$$

Without loss generality, we can assume that $\mathrm{L}=1+5^{n}$ and $\mathrm{z}=5^{p}$

Then above equation is reduced as $x^{n}+y^{n}=L z^{n}$

TABLE 7: We can verify the triplets $(\mathrm{x}, \mathrm{y}, \mathrm{z})$ are satisfies above equation by taking some values of $p \& n$ 


\begin{tabular}{llllllll}
\hline $\mathrm{n}$ & $\mathrm{p}$ & $\mathrm{X}=$ & $\mathrm{Y}=$ & $\mathrm{Z}=$ & $L$ & $x^{n}+$ & $\mathrm{L} z^{n}$ \\
& & $5^{p}$ & $5^{p+1}$ & $5^{p}$ & $\begin{array}{l}y^{n} \\
+5^{n}\end{array}$ & \\
& & & & \multicolumn{5}{l}{} \\
1 & 1 & 5 & 25 & 5 & 6 & 30 & 30 \\
2 & 1 & 5 & 25 & 5 & 26 & 650 & 650 \\
2 & 2 & 25 & 125 & 25 & 26 & 16250 & 16250 \\
3 & 1 & 5 & 25 & 5 & 126 & 15750 & 15750 \\
3 & 2 & 25 & 125 & 25 & 126 & 196875 & 196875 \\
& & & & & & 0 & 0 \\
4 & 1 & 5 & 25 & 5 & 626 & 391250 & 391250 \\
\hline
\end{tabular}

Clearly $\mathrm{L}$ is greater than 1 . It follows that Fermat's last theorem is verified for " No positive integers $\mathrm{x}, \mathrm{y}, \mathrm{z}$ are satisfies the equation $x^{n}+y^{n}=z^{n}$ for any integer $n>2$.

We can continue above procedure, with representing $\mathrm{x}$ and $\mathrm{y}$ in terms of different prime exponents of all integers and their corresponding arithmetical operations, we observed that in every case $\mathrm{K}$ and $\mathrm{L}$ are must be more than 1 , It follows that for $\mathrm{n}>2$, It is not possible to find three positive integers $\mathrm{x}, \mathrm{y}$, $\mathrm{z}$ with $\mathrm{K}=1, \mathrm{~L}=1$. In this way we can proved Fermat's Last theorem.

Conclusion In this paper we are presented for $\mathrm{n}>2$, Diophantine equations $\mathrm{K}\left(x^{n}+y^{n}\right)=z^{n}$ and $x^{n}+y^{n}=L z^{n}$ are satisfied by some positive prime exponents of $\mathrm{x}, \mathrm{y}, \mathrm{z}$ with sufficient values of $\mathrm{K}$ and $\mathrm{L}$. But it is not possible to find positive integers $\mathrm{x}, \mathrm{y}$ and $\mathrm{z}$, which are satisfies above equations with $\mathrm{K}=1$ and $\mathrm{L}=1$. Clearly it proves the Fermat's last theorem, which states that No positive integers of $x, y, z$ are satisfies the equation $x^{n}+y^{n}=z^{n}$ for $\mathrm{n}>2$.

References:

[1] Fermat's Last Theorem, in Encyclopedia

[2] Fermat's Last Theorem, Wolfram Math World.

[3] Fermat's Last Theorem, Mac tutor, History of Mathematics. 